\title{
Evolución de las especies por cooperación natural
}

Evolution of species by natural cooperation

Recibido: abril 03 de 2020 | Revisado: setiembre 09 de 2020 | Aceptado: diciembre 20 de 2020

EuMÉNIDES VALQUi-ZuTA ${ }^{\mathrm{I}}$

Resumen

La vida evoluciona, pero el mecanismo de este proceso -aceptada por la biología moderna- es la selección natural: Darwin (1983) permite la supervivencia de los más aptos en la lucha por la vida; concepción basada en luchas antagónicas y violentas que premian a los más aptos; inspiración colonialista propia de la Inglaterra victoriana. Sin embargo, un ser vivo o una especie no pueden ser concebidos con entes aislados luchando por sobrevivir; sino en relación con los demás seres y el medio; es una visión holística de la existencia, donde el proceso evolutivo responde a mutuas relaciones de interdependencia y cooperación sin que esto niegue la existencia del conflicto en el proceso evolutivo. Concibo a la cooperación natural como el mecanismo natural fundador y constante de la evolución, el camino que lleva a la novedad evolutiva; sin embargo, esta cooperación, como manifestación de la paz natural, no es perfecta, es inacabada y en proceso, dinámica en el tiempo y el espacio. La cooperación natural imperfecta son aquellas realidades colaborativas e interrelaciones que permiten a los seres orgánicos obtener los resultados más favorables y viables para sortear los conflictos que dificultan la evolución como novedad biológica.

Palabras clave: Evolución, paz imperfecta, cooperación natural, conflicto, giro epistemológico

\begin{abstract}
It is a fact that life evolves, but the mechanism - currently accepted - of this process is called natural selection (Darwin, 1859), which would allow the survival of the fittests in the fight for life; conception based on antagonistic and violent struggles, which reward the fittests; colonialist vision, typical of Victorian England. A living being or a species cannot be conceived as an isolated entity that struggles to survive; if not in relation to other beings and the environment; it is a holistic vision of existence, where the evolutionary process responds to mutual relationships of interdependence and cooperation, without denying the existence of the conflict within the evolutionary process. Using the deconstructive-reconstructive philosophical methodology, I conceive of natural cooperation as the founding and constant natural mechanism of the evolution of life; the path that leads to evolutionary novelty. This cooperation, as a manifestation of natural peace, is not perfect; it is unfinished given its dynamic character in time and space, it is a perfectible cooperation that coexists with many conflicts. Imperfect natural cooperation are those collaborative realities and interrelationships that allow organic beings to obtain more favorable results to avoid the conflicts that hinder evolution; a response and natural strategy in the complexity of life. The life of the predator depends on its victim, but as disastrous as it may seem, the victim population persists; maintaining despite this imperfection - the balance in nature.
\end{abstract}

1 Universitat Jaume I-Castellón de la Plana - España evalquizuta@gmail.com
Key words: evolution, imperfect peace, natural cooperation, conflict, epistemological

(C) Los autores. Este artículo es publicado por la Revista Campus de la Facultad de Ingeniería y Arquitectura de la Universidad de San Martín de Porres. Este artículo se distribuye en los términos de la Licencia Creative Commons Atribución No-comercial - Compartir-Igual 4.0 Internacional (https://creativecommons.org/licenses/ CC-BY), que permite el uso no comercial, distribución y reproducción en cualquier medio siempre que la obra original sea debidamente citada. Para uso comercial contactar a: revistacampus@usmp.pe.

https://doi.org/10.24265/campus.2021.v26n31.05 


\section{Introducción}

Desde hace 15 décadas la teoría del origen de las especies concebida por Charles Darwin ha merecido un creciente interés, no solo desde sus inicios sino a lo largo de todo el tiempo transcurrido. Darwin en El origen de las especies rebate de una vez por todas las ideas predominantes de su época, según las cuales las especies vivas descendían en línea recta y sin variación de una pareja progenitora original.

Ante esto Darwin propone la hipótesis de la variabilidad las cuales eran seleccionadas naturalmente. Las variaciones eran producidas por las adaptaciones del organismo a su medio; por tanto, la adaptación del ser vivo a las condiciones cambiantes del medio era la manera como la selección natural introducía variaciones, las cuales por muy mínimas que fueran permitía la supervivencia del más favorecido o apto. Pero si la selección natural permitía la supervivencia de los más aptos desde la perspectiva de la adaptabilidad, entonces cabe la idea de un principio: la lucha por la vida, como lo entendió Darwin (1983); sin embargo, no es una lucha desleal, sino que el éxito de los llamados aptos es el resultado de un complejo proceso de interrelaciones entre los miembros de la especie, entre estos y las otras especies con las cuales convive y con el medio circundante. En la base de estos procesos de interrelaciones se encuentran procesos de cooperación, sin los cuales el proceso evolutivo simplemente no podría haber funcionado.

Es en el marco de la teoría de Darwin y los postulados de cooperación desde la Filosofía para la paz de la Cátedra
UNESCO de la Universitat Jaume I, Castellón de La Plana-España, que inspira el presente trabajo de investigación, cuyo propósito principal es analizar y valorar la relación que existe entre el origen y éxito de las especies que pueblan nuestro planeta con la cooperación considerada como natural; de esta manera, la selección natural que constituye el mecanismo darwiniano principal para la evolución de las especies no sería la visón correcta; por el contrario, el mecanismo evolutivo tendría un ingrediente fuertemente cooperativo y pacífico, contrariamente a las concepciones tradicionales basadas en luchas antagónicas y violentas, que premian a los más aptos en el contexto del paradigma de la competencia.

De esta manera, el presente trabajo guarda relación con el paradigma emergente de sentirnos parte de la Tierra, de volver la mirada hacia nuestros orígenes, de firmar la paz con la Tierra, contrariamente al tradicional paradigma de entender el mundo y la naturaleza como un gran almacén del cual podemos coger lo que queramos sin preocuparnos por nada más que el egoísta apetito personal.

\section{Método}

Partiendo que la conflictividad es una característica inherente a los seres humanos y al medio que nos rodea, y que muchos de estos conflictos los viabilizamos $o$ transformamos por medios violentos; pretendo deconstruir, de la mano con los aportes de los estudios de Filosofía para la paz y una cultura para la paz, los fundamentos de éxito que tienen las especies más fuertes y capaces en el curso de la evolución planteada por Charles Darwin, de tal modo que no se 
justifica la eliminación de las especies más débiles o menos favorecidas del escenario histórico.

De esta manera, desde la interdisciplinariedad y la perspectiva holística, busco deconstruir la interpretación violentológica enquistada directa o indirectamente en la teoría darwinista de la evolución de las especies y ofrecer una visión fundada en la convivencia y cooperación entre las especies y entre éstas con el medio ambiente en el camino evolutivo de las mismas. Los conflictos -no pocos por cierto- presentes en el proceso evolutivo, no constituyen un mal terrible que devienen en violencia, sino se transmutan en oportunidades cooperativas que impulsaron la evolución y lo continúan haciendo en la historia de la vida en nuestro planeta. Consecuentemente trataré de interpretar la evolución de la vida en nuestro planeta, basado en presupuestos del giro epistemológico, la concepción positiva del conflicto y la paz imperfecta, interpretar la evolución como un proceso dirigido por cooperación natural.

En consonancia con el campo transdisciplinar de la paz, que busca dar respuestas a la conflictividad y complejidad reconoce las interacciones entre conflictos, violencias, paces, culturas, disciplinas, saberes, teorías; así como, sentimientos; considera el carácter imperfecto de la paz. Utilizo como herramienta la propuesta de una matriz unitaria comprensiva e integradora que incluya a todos los saberes expresados como teoría sobre el proceso evolutivo de las especies, así como a los actores mismos de este proceso: los seres vivos - como especies que evolucionan - en interdependencia con el medio o contexto físico. De este modo, pretendo abordar la complejidad de las interrelaciones interdependientes que se manifiestan en el proceso evolutivo, y que en consecuencia se presenten resultados de comprensión del hecho evolutivo no solamente diferentes a las teorías dominantes y casi dogmáticas, sino más acorde con la realidad y con una apertura a escuchar a nuevas propuestas. La matriz unitaria, propuesta por Muñoz (2001), permitirá correlacionar al proceso evolutivo con los múltiples conflictos que se suceden en el mundo vivo y en consecuencia optar por una respuesta a esta conflictividad natural desde la perspectiva de la paz imperfecta. En esta perspectiva y para llevar adelante dicha matriz, me apoyo en el giro epistemológico, en la teoría del conflicto desde la filosofía para la paz y en la paz imperfecta.

El presente estudio es de tipo descriptivo-cualitativo, por ello, en base a un marco teórico-informativo y a las evidencias recogidas por investigadores especialistas en el tema, refiero e interpreto conexiones existentes o que se relacionan en el análisis de la selección natural con la cooperación de las especies a lo largo del proceso evolutivo.

\section{Darwin y la selección natural}

La evolución de la vida es un hecho consumado. Hoy es indiscutible el proceso evolutivo como realidad en nuestro planeta, que llevó a la vida desde su existencia ancestral hasta lo que hoy conocemos en sus más diversas formas; un estallido maravilloso de variedades que pueblan los más recónditos lugares, todo lo cual han devenido en lo que llamamos: biodiversidad. 
Sin embargo, una cosa es el hecho evolutivo y otra la teoría que trata de explicar el cómo se produce la evolución biológica. Una de estas teorías, la más extendida, aceptada, defendida y tenida como hegemónica es la evolución por selección natural, teoría propuesta hace 161 años por Charles Darwin (1859) y Alfred R. Wallace. Actualmente, la selección natural es el concepto central de la teoría de la evolución biológica. Evolución y selección natural son dos conceptos totalmente diferentes, ni tampoco necesariamente a priori, deben permanecer juntos.

La evolución es un hecho y proceso natural continuo, un conjunto de cambios producidos en sucesivas generaciones que permiten multiplicar y diversificar la vida en nuestro planeta. El proceso evolutivo queda de manifiesto por la existencia del registro fósil, los órganos y funciones tanto comunes como vestigiales entre seres de diferentes especies, la similitud en la etapa embrionaria de especies con ancestros comunes, la base molecular tanto de estructuras celulares, tejidos y órganos como la base molecular responsable de la herencia con el $\mathrm{ADN}$ y ARN.

La selección natural es una teoría que trata de explicar cómo se produce la evolución de los seres vivos, de modo que como teoría científica, la selección natural está sujeta a observaciones, críticas y posible refutación. El centro de la teoría de la selección natural es la reproducción diferencial de unas variantes, genéticamente con mayores aptitudes respecto de otras, solo viven los más aptos, los más capaces, los más fuertes, aquellos que pueden destruir a otros y quedarse con la subsistencia, de esta manera Darwin y los neodarwinistas conceden un lugar privilegiado a la lucha como única condición para existir. Los débiles no tendrían oportunidad de dejar descendencia. "He denominado a este principio, por el cual toda variación ligera, si es útil, se conserva, con el término de "selección natural", a fin de señalar su relación con la facultad de selección del hombre. Perola expresión, frecuentemente, empleada por Mr. Herbert Spencer de «supervivencia de los más aptos» es más exacta $y$, a veces, igualmente conveniente» (Darwin, 1983: 116). El darwinismo considera tres ejes fundamentales para que se verifique la evolución: variación, selección natural y adaptación. Para dar sustento a la selección natural, Darwin traslada las teorías socioeconómicas (no por ello se cuestiona) de Adam Smith y Thomas Malthus al campo de la biología, y establece el núcleo de su teoría; la competencia y la lucha por la existencia son los principales actores en la evolución de las especies. Interpretando a Malthus, considera que la capacidad de reproducción de las especies supera con creces los recursos existentes, en consecuencia, se presenta un estado de competencia continua entre los individuos de una misma especie y diferentes especies. Aquellos individuos que por sus características guardan mejor sintonía con las características circundantes del momento, resultan con mayor ventaja competitiva respecto a los demás, finalmente estos individuos mejor dotados, mejor conformados y/o más adecuados, son los que sobreviven $\mathrm{y}$ se reproducen con mayor frecuencia. Esta competencia constante y adaptativa, que funciona a manera de tamiz, es lo que Darwin denomina selección natural; no olvidemos que Herbert Spencer en el ámbito de la sociología, lo definió como la supervivencia del más adecuado. 
Consecuentemente, la selección natural es concebida como un proceso muy lento: "Que la selección natural obra generalmente con extrema lentitud, lo admito por completo» (Darwin, 1983: 169), es pertinente a los seres vivos, favorece su variación, multiplicación y transmisión de la herencia, teniendo como resultados intrínsecos de esta dinámica evolutiva la producción de órganos, la aparición de estructuras, características y conductas diseñadas para asegurar la supervivencia y la reproducción de las especies, logrando de esta manera su presencia en el tiempo. La selección natural puede ser resumida como una serie de eventos caóticos afortunados, como procesos ciegos y mecánicos que se repiten a lo largo de millones de años y que por casualidad aparecen invenciones espectaculares que si encajan con las condiciones ambientales del momento, el ser tiene éxito y derecho en la escena de la vida.

\section{Teorías emergentes sobre evolución}

La perspectiva de una evolución violenta alimentada por la lucha, competencia y odio no encaja en la naturaleza; esta no es una idea fríamente reivindicatoria, al contrario; se evidencia una naturaleza llena de interrelaciones, donde una especie depende de otra y está de otras; el mundo inanimado es fuente de materia y energía su ausencia provocaría la desaparición de la vida, la cual existe porque parece que todo se confabula de tal manera que pueda pulular la vida.

El reduccionismo mecanicista de la ciencia darwinista donde el azar y la lucha son los motores evolutivos, queda rebasada por la complejidad de las formas de vida, por las interrelaciones cooperativas; la integración y autoorganización entre los factores de los ecosistemas inspiran una nueva forma de abordar el hecho evolutivo, se hace necesario una nueva mirada, un nuevo paradigma está aflorando de modo tal que el paradigma darwinista se encuentra en el centro de una crisis epistemológica. "¿Qué brillantez u originalidad existen en tomar una idea social y aplicarla a la naturaleza?

Ciertamente la de concluir la construcción de la metafísica social liberal, transformándola en reglas naturalistas» (Abdalla Guerrieri, 2009: 17). Es necesario un giro epistemológico, "Solo recientemente este modelo tradicional de ciencia está siendo cuestionado, especialmente por su carácter dominante y aniquilador de otros saberes bajo un supuesto velo de neutralidad y objetividad" (Comins Mingol, 2005: $6)$; se hace necesario considerar una ciencia y una teoría de la evolución que deje de lado el trasnochado eslogan de neutralidad, objetividad, racional y empírica. No existe tal visión de ciencia, de una u otra manera la ciencia que es tarea de seres humanos, se ve influenciada por nuestros sentimientos, la cultura y la forma de vida de nuestra sociedad, nada es neutro, somos nosotros quienes interpretamos a la naturaleza y no al revés, nosotros cambiamos nuestra mirada respecto a ella, la naturaleza solamente está allí existiendo a través del tiempo independiente de nuestras maneras de interpretarla.

De esta manera, estamos frente a un nuevo paradigma que considera al conflicto como una serie de eventos que no solamente ofrecen oportunidades de cambio sino nuevas maneras de establecer nexos entre las partes en conflicto, y esto 
es lo que se observa en la naturaleza. Si un ser vivo tiene dificultades alimenticias o de otra índole: materiales, hábitat, etc. busca establecer nexos para proporcionarse aquello que hace falta, busca estrategias de cooperación, en vez de competición, lucha y violencia; imaginemos por un momento que fuera lo contrario, como resultado de la competencia y lucha hace tiempo que las especies se hubieran aniquilado, porque tal es el rumbo de la violencia. De otro lado, por donde vayamos ora en el mundo inanimado, ora en el animado, se evidencia una red de conexiones todas cada vez más complejas tendientes a mantener y proliferar la vida en nuestro planeta. Muchas son las teorías que ponen en tela de juicio la selección natural darwinista; así tenemos:

La teoría endosimbiótica serial de Lynn Margulis, explica las relaciones simbióticas en el proceso evolutivo de la célula procariota a célula eucariota. La génesis de algunos orgánulos típicos de las células eucariotas: plastos, mitocondrias, cilios y flagelos, habrían tenido origen en organismos procariotas anteriormente de vida individual como bacterias, y que después de ser englobados por otro microorganismo habrían establecido una relación endosimbiótica con éste. Se postula que las mitocondrias procederían de proteobacterias alfa, comolas rickettsias por ejemplo, y los plastos provendrían de cianobacterias: «En primer lugar, un tipo de bacteria amante del azufre y del calor, llamada arqueobacteria fermentadora (o termoacidófila), se fusionó con una bacteria nadadora. Juntos, los dos componentes integrados de la fisión se convirtieron en el nucleocitoplasma, la sustancia base de los ancestros de las células animales, vegetales y fúngicas» (Margulis, 2003: 88), así se formaría el núcleo celular, posteriormente se produjo una nueva incorporación que dotaría al primigenio eucarionte, la capacidad para metabolizar el oxígeno: « [...] otro tipo de microbio de vida libre fue incorporado a la fusión: una bacteria que respira oxígeno" (Margulis, 2002: 48). De esta manera una nueva especie se originaba mediante un proceso simbiótico.

El español Máximo Sandín propone una alternativa diferente para explicar la variabilidad de la especies en función de la variabilidad del material hereditario: La integración de sistemas complejos. Sandín nos coloca en el centro mismo de los procesos moleculares de la vida, los genes no serían entidades aisladas que transmiten un carácter, es decir un gen un carácter, por el contrario están inmersos en una red de interacciones, en una interdependencia tal que sería imposible entenderlo de manera aislada y basada en mutaciones al azar, se hacen necesarias macromutaciones, alteraciones enormes que explique la variabilidad de las especies, pero ¿cómo?

La respuesta pasa por considerar al papel de los virus como transportadores de información genética, al introducir secuencias complejas de genes dentro de las células existentes. «La infección vírica de un numeroso grupo de organismos (animales o plantas) haría posible la aparición simultánea de las nuevas características, condición indispensable para su perpetuación (frente a la mutación de un solo individuo,...)» (Sandín, 1995: 73). Esto explicaría los saltos bruscos que hacen referencia el registro fósil en especial el periodo Cámbrico, además, cómo una especie se transforma o da origen a otras; como se referencia existe una interrelación virus-células de especies 
preexistentes, lo cual dista mucho de la selección natural.

La hipótesis Gaia de James Loovelock considera que: «la materia viviente de la Tierra y su aire, océanos y superficie forman un sistema complejo al que puede considerarse como un organismo individual capaz de mantener las condiciones que hacen posible la vida en nuestro planeta» (Lovelock, 1985: 4). De esto se desprende, que Lovelock en modo alguno considera a la Tierra como un ser viviente y consciente, como muchos han querido interpretar a la teoría para desvirtuarla; al respecto precisa: «[...] deseo subrayar que ello no va más allá del grado de personalización que a un navío le confiere su nombre, reconocimiento a fin de cuentas de la identidad que hasta una serie de piezas de madera y metal puede ostentar cuando han sido específicamente diseñadas y ensambladas, del carácter que trasciende a la simple suma de sus partes» (Lovelock, 1985: 6).

Queda claro la noción de Gaia como un todo, una Tierra viviente inmensa en sus interrelaciones de autorregulación; de manera que la hipótesis Gaia dista mucho de considerar a la Tierra como un único organismo, como un ser de la esfera teológica, peor aún mítica; es reconocer que la vida en el planeta tiene su fundamento en procesos complejos interrelacionados que inciden además en el mantenimiento del medio ambiente el cual a su vez mantiene la vida, y así una suerte de bucle global.

\section{Evolución por cooperación natural}

Un ser vivo o una especie no puede ser concebida como un ente aislado que lucha para sobrevivir; sino en relación con los demás seres y el medio; es una visión holística de la existencia - en consonancia con los presupuestos de Fisas (2001) - , donde el proceso evolutivo responde a mutuas relaciones de interdependencia y cooperación sin que esto niegue la existencia del conflicto en el seno del proceso evolutivo. Concibo a la cooperación natural como el mecanismo natural fundador y constante de la evolución de la vida; como el camino que lleva a la novedad evolutiva; sin embargo, esta cooperación, como manifestación de la paz natural, no es perfecta, es inacabada, está en constante proceso dado su carácter dinámico en el tiempo y el espacio, es una cooperación perfectible por la existencia de muchos conflictos; de esta manifestación del hecho evolutivo se desprende la cooperación imperfecta cuyo fundamento teórico está inspirado en la paz imperfecta.

\section{La cooperación natural imperfecta} son aquellas realidades colaborativas, interrelaciones que permiten a los seres orgánicos obtener los resultados más favorables y viables para sortear los conflictos que dificultan la evolución como novedad biológica; es una respuesta y estrategia natural en la complejidad de la vida. Ello explica, por ejemplo la evolución dinámica e interrelacionada en animales, como león-gacela, puma-venado, gatoratón, vacas-pasto, arañas-moscas; etc. la vida del depredador depende de su víctima, pero muy desastroso que parezca las víctimas como población persisten en el tiempo; manteniéndose -a pesar de esta imperfección- el equilibrio en la naturaleza, ni los depredadores han perecido de hambre con la consecuente eliminación de su especie; ni las presas han desaparecido como especie, con la muerte de algunos de sus miembros 
colaboran en la preservación de la vida de sus depredadores, por esto no puede ser una cooperación perfecta.

En un sentido amplio, la cooperación natural, se yergue como antítesis de la selección natural y en consecuencia descarta a la competición, lucha por la existencia y a los sucesos aleatorios o fortuitos como fundamentos evolutivos.

Pero ¿’Por qué tiene éxito la selección natural? Nuestra cultura asocia el conflicto a la violencia, es decir; el conflicto necesariamente debe terminar en violencia o lucha para que tal conflicto desaparezca; esto es un error; violencia y conflicto son dos conceptos diferentes. «El conflicto es un fenómeno que se produce de manera natural y no tiene por qué ser negativo. Posee potencialidades positivas y cuando surge puede ayudarnos a fortalecer dimensiones en la relación que no había aflorado anteriormente» (Pérez Serrano y Pérez de Guzmán, 2011: 21). De esta manera, la ocurrencia de violencia o lucha están asociados a la transformación negativa del conflicto. «Estas nociones son evidentes cuando nos damos cuenta de que la violencia lleva a una concepción negativa de los conflictos» (París Albert, 2009: 24); esta forma de tratar el conflicto solo lleva a la degradación de las relaciones, a eliminar el proceso constructivo inherente al conflicto, se hace necesaria una nueva visión; una perspectiva positiva del conflicto, mediante la cual si aceptamos que el «conflicto es indispensable para el crecimiento humano, hemos de concretar una visión creativa del conflicto que concuerda con la comprensión de la paz» (Lederach, 2000: 59).

En el ámbito evolutivo, la concepción negativa del conflicto, llevaría necesariamente a minar no solamente la convivencia entre seres vivos, sino a poner en peligro su misma existencia. Esta perspectiva del conflicto, que no fue ajena a Darwin en la época victoriana, tampoco para sus seguidores, se presenta porque «vivimos en una cultura que ensalza la competitividad y la violencia» (Pérez Serrano y Pérez de Guzmán, 2011: 21). Contrariamente a esto, el conflicto en la naturaleza se torna en formas de interacción, donde si bien es cierto, hay ruptura de relaciones, sin embargo la naturaleza busca salvar creativamente tales dificultades para dar continuidad a la vida, no olvidemos que la vida en nuestro planeta y el entorno tienen la tendencia hacia el equilibrio. Además, no es posible precisar la unidad de evolución o unidad de selección como lo denota el darwinismo.

$\mathrm{Al}$ respecto, y desde el darwinismo, unos proponen que es el gen, otros la célula, para algunos el individuo, otros la población, conforme a MaedaMartínez, 2002; en tanto que también existe quienes consideran a la especie como la unidad evolutiva. Considero, que ninguna de las unidades evolutivas propuestas se constituye en niveles base sobre los cuales se asienta el proceso evolutivo. Los genes solos no trascienden a menos que se encuentren dentro de la célula donde establecen interrelaciones para manifestar su acervo génico; las células para poder trascender necesitan indefectiblemente de materiales y energía de su entorno sin lo cual jamás podrían tener un atisbo de vida, las células solas no evolucionan, en cuanto a los individuos multicelulares como reunión de muchas células, un cambio en uno de ellos no repercutirá significativamente en la 
generación de una especie, además ¿cómo se explica la evolución del altruismo o la misma cooperación en este nivel o el de los grupos?, ningún individuo sobrevive solo y esto se aplica a los grupos y también a las especies las cuales necesitan de los individuos que lo conforman y del medio circundante; absolutamente todo está interrelacionado, es el todo el que evoluciona, es la complejidad de esas interrelaciones la que trae la novedad evolutiva.

No existen genes egoístas, no hay lugar para la separación en ninguno de los niveles: atómico-moleculares, genes, células, tejidos, órganos, sistemas, individuos, poblaciones, especies, ecosistemas; absolutamente todo se encuentra interrelacionado, en interdependencia mutua, en cooperación, la cual es una realidad natural, aunque imperfecta. La hipótesis Gaia nos recuerda esta interrelación a escala global donde los seres vivos se deben al medio ambiente, a los factores físicos; pero éstos también se deben a la vida; nuestro planeta y la vida sobre él, se debe a la cooperación.

Las ciencias biológicas tienen una clara perspectiva violentológica en la interpretación de la evolución de la vida, la cual «no está exenta de una cierta disonancia cognoscitiva a veces cercana a la esquizofrenia. Puesto que se desea, se busca, se valora más la paz, pero sin embargo se piensa en claves de violencia» (Muñoz, 2001: 22). La perspectiva de una evolución violenta alimentada por la lucha, competencia y odio, cambia; pero no cambia porque se enarbolan ideas fríamente reivindicatorias, sino porque la realidad nos dice lo contrario; se evidencia una naturaleza llena de interrelaciones, donde una especie depende de otra y está de otras; el mundo inanimado es fuente de materia y energía su ausencia provocaría la desaparición de la vida, la cual existe porque parece que todo se confabula de tal manera que pueda pulular la vida. El reduccionismo mecanicista de la ciencia darwinista donde el azar y la lucha son los motores evolutivos, queda rebasado por la complejidad de las formas de vida, por las interrelaciones cooperativas, la integración y auto organización entre los factores de los ecosistemas inspiran una nueva forma de abordar el hecho evolutivo, se hace necesario una nueva mirada, un nuevo paradigma está aflorando de modo tal que el paradigma darwinista se encuentra en el centro de una crisis epistemológica.

Es necesario un giro epistemológico, giro que considere una ciencia y una teoría que explique el proceso de evolución, que deje de lado el trasnochado eslogan de neutralidad, objetividad, racional y empírica. No es real tal visión de ciencia, de una u otra manera la ciencia que es tarea de seres humanos, se ve influenciada por nuestros sentimientos, la cultura y la forma de vida de nuestra sociedad, nada es neutro. «El intelecto, del que los seres humanos nos sentimos tan orgullosos, solo tantea el dorso de las cosas, no su verdad. Se nos ha hecho creer que la verdad era la referencia adecuada a las cosas» (Martínez Guzmán, 2000: 60); somos nosotros quienes interpretamos a la naturaleza y no al revés, nosotros cambiamos nuestra mirada respecto a ella, la naturaleza solamente está allí existiendo a través del tiempo independiente de nuestras maneras de interpretarla.

De esta manera, estamos frente a un nuevo paradigma que considera al 
conflicto como una serie de eventos que no solamente ofrecen oportunidades de cambio sino nuevas maneras de establecer nexos entre las partes en conflicto, y esto es lo que se observa en la naturaleza. Si un ser vivo tiene dificultades alimenticias o de otra índole: materiales, hábitat, etc. busca establecer nexos para proporcionarse aquello que hace falta, busca estrategias de cooperación, en vez de competición, lucha y violencia; imaginemos por un momento que fuera lo contrario, como resultado de la competencia y lucha hace tiempo que las especies se hubieran aniquilado, porque tal es el rumbo de la violencia. De otro lado, por donde vayamos ora en el mundo inanimado, ora en el animado, se evidencia una red de conexiones todas cada vez más complejas tendientes a mantener y proliferar la vida en nuestro planeta.

La evolución es el camino que la naturaleza inventó para que la vida transcurriera en múltiples y variadas formas y manifestaciones, más la forma de caminar en este proceso es la cooperación natural, una de las aristas de la paz.

\section{Resultados}

Estamos frente a un nuevo paradigma que considera al conflicto como una serie de eventos que no solamente ofrecen oportunidades de cambio sino nuevas maneras de establecer nexos entre las partes en conflicto, y esto es lo que se observa en la naturaleza.

$\mathrm{Si}$ un ser vivo tiene dificultades alimenticias o de otra índole, como: materiales, hábitat, pareja reproductiva, etc. busca establecer nexos para proporcionarse aquello que hace falta, busca estrategias de cooperación, en vez de competición, lucha y violencia. Los seres vivos se encuentran interrelacionados entre ellos y con todos los elementos de nuestro planeta, con el objetivo de la continuidad de la vida. La evolución es el camino que la naturaleza inventó para que la vida transcurriera; más su mecanismo o el ¿cómo? se desarrolla el hecho evolutivo dista de ser el resultado selectivo de los más aptos o fuertes; por el contrario, se evidencian interrelaciones y mutua dependencia. La visión de un mundo interrelacionado es más realista que un mundo en constante lucha y competencia.

\section{Conclusiones}

Las especies evolucionan entablando relaciones de mutua interdependencia con los demás seres vivos y con el medio que los rodea; tales interdependencias son de carácter colaborativo, luego, el mecanismo evolutivo es la cooperación natural, una manifestación natural de la paz. Para comprender la evolución de las especies se hace necesario un giro epistemológico, superar el tradicional paradigma de la competición darwinista por un nuevo paradigma: el paradigma de la cooperación. Tal cooperación, debido a la existencia natural de conflictos, se torna en cooperación imperfecta como manifestación de la paz imperfecta. La selección natural darwinista no juega un papel relevante en la evolución, el papel selector se reduciría a elegir aquello que ya existe, la criba de la selección operaría después que se establecieron las relaciones cooperativas que permiten la vida y la evolución. 


\section{Referencias}

Abadalla Guerrieri, M., Agudelo Murguía. G y Sandín Domínguez, M. (2009. Darwin, el sapo y la charca, Sevilla: Ediciones Crimentales y Cauac Editorial.

Comins Mingol, I. (2005). «Reseña de Podemos Hacer las Paces. Reflexiones éticas tras el 11-S y el 11-M de Vicent Martínez Guzmán». Convergencia. Revista de Ciencias Sociales, vol. 12, Número 38, mayo-agosto, 2005, pp. 377384, Universidad Autónoma del Estado de México.

Darwin, C. R. (1983). El origen de las especies. Madrid: Sarpe.

Fisas, Vicenç (2001). Cultura de paz $y$ gestión de conflictos. Barcelona: Icaria.

Lederach, J. P. (2000). El abecé de la pazy los conflictos. Educación para la paz, Madrid: Catarata.

Lovelock, J. (1985). Gaia, una nueva visión de la vida sobre la Tierra. Barcelona: Ediciones Orbis. S.A.

Maeda-Martínez, Alfonso N. (2002): Los Moluscos Pectinidos de Iberoamérica: Ciencia y Acuicultura, México D.F: Limusa.
Margulis, L. (2003). Una Revolución en la Evolución. Escritos seleccionados, Valencia: Universidad de Valencia.

Margulis, L. (2002). Planeta Simbiótico. Un nuevo punto de vista sobre la evolución, Madrid: Editorial Debate.

Martínez Guzmán, V. (2000). «Saber hacer las paces. Epistemologías de los Estudios para la Paz», Convergencia, Revista de Ciencias Sociales, no 23, 49-96.

Muñoz, Francisco A. (2001). «La paz imperfecta en un universo en conflicto", en Muñoz Francisco A. (Ed.): La paz imperfecta, Granada, Universidad de Granada. pp. 21-66.

París Albert, S. (2009). Filosofía de los conflictos. Una teoría para su transformación pacifica. Barcelona: Icaria.

Pérez Serrano, G. M. y Pérez de Guzmán, V. (2011). Aprender a convivir. El conflicto como oportunidad de crecimiento. Madrid: Narcea.

Sandín Domínguez, M. (1995). Lamarck $y$ los mensajeros. La función de lo virus en la evolución. Madrid: Ediciones Istmo. 
